\title{
All Aspects of Nursing Care are Equally Important
}

\section{Franjic $S^{*}$}

Faculty of Law, International University of Brcko District, Bosnia and Herzegovina

*Corresponding author: Sinisa Franjic, Faculty of Law, International University of

Brcko District, Brcko, Bosnia and Herzegovina, Tel: +387-49-49-04-60; Email: sinisa.franjic@gmail.com

\section{Review Article}

Volume 3 Issue 2

Received Date: March 13, 2019

Published Date: March 28, 2019

DOI: $10.23880 /$ nhij- 16000184

\section{Abstract}

Modern nursing began to develop in the 19th century as a moral practical component of patient care, and in the second half of the $20^{\text {th }}$ century, it affirmed itself as a separate occupation. Lifting nursing education to the academic level has paved the way for further development of nursing, and nursing affirms and defines itself as an autonomous profession, and nursing ethics as a separate discipline. Nurses did not allow the scientific rise of nursing education to the academic level to lose the "core" of the nursing profession - care for the patients. In the care of the patient, their families have an important role in the measurement which modern medicine and health allow that. Nurses and families have to cooperate in health care for the patients.

Keywords: Nursing; Nurses; Education; Healthcare; Ethics

\section{Introduction}

Specialist practice was defined as a type of specialised clinical role that required the nurse to exercise the highest levels of judgement and discretion in clinical care ... demonstrate higher levels of clinical decision making ... monitor and improve standards of care through supervision of practice, clinical nursing audit, developing and leading practice, contributing to research, teaching and supporting professional colleagues' [1]. In contrast, advanced practice involved 'adjusting the boundaries for the development of future practice, pioneering and developing new roles responsive to changing needs and, with advancing clinical practice, research and education, to enrich professional practice as a whole'. The development and achievement of both these forms of nursing practice was dependent not only on those individuals working in such roles but also to a great extent on the active support of NHS (National Health Service) trust managers. Job descriptions, where they existed, were invariably non-standard, tailored to individuals in particular posts in specific areas with little commonality between them even in the same trust. The grading of posts, employment conditions, work activities and concerns about the interface between advanced practice and medicine all emerged as matters requiring attention. Added to this was a lack of understanding, among senior managers, regarding the differences between specialist and advanced nurse practitioners.

What is immediately and abundantly clear is that the advanced nurse practitioner has been, and remains, a complex and controversial concept, and an issue that has engendered enormous debate in the nursing profession [2]. In addition it is a concept (a role, a level of practice) that has long been promoted by health strategists as a mechanism to overcome healthcare manpower shortages by enabling new clinical roles that can be used to promote healthcare quality and service delivery. Despite the strategists' positive promotion of advanced nurse practitioners, the education of such practitioners has been an erratic and unregulated affair that has lacked any 


\section{Nursing \& Healthcare International Journal}

central coherency until most recently. Consequently, the standards of practice and competence held by those who claim to be advanced nurse practitioners varies widely. It is this situation that has led to the long debate on how advanced practice may be defined and measured. That endeavour has been grounded in the professional and public concern over the profession's ability to ensure that advanced nurse practitioners are fit for practice within any of the four initial registrant fields of nursing practice, including those working with children and young people.

\section{Healthcare}

Health is a state of complete physical, mental and social well-being, and not just freedom from disease or disability is definition of the World Health Organization means that the quality of health care must not only individuals but also society as a whole [3]. When considering the issues of health, there is no dilemma for medical professionals because every man, regardless of gender or skin color, who seeks professional medical assistance approaches the same way or practices according to the profession's rules to help him with his competences. This is one of the fundamental principles of medical ethics that is respected by medical professionals anywhere in the world. Thus, the quality of health and health care is achieved not only in the environment where medical help is required, but society as a whole.

Caring is the essence of being human, and nursing is a deeply human relationship; thus, caring is the essence of nursing [4]. The meaning of caring as the essential nature of humanness cannot be encapsulated within a single limiting definition; however, caring can be understood, recognized, and developed both philosophically and practically. Caring expressed in nursing is the intentional and authentic presence of the nurse with another who is recognized as a person who is living caring and growing in caring. All human service disciplines are based on caring. Nursing is unique, however, as caring is what most directly characterizes nursing's knowledge base and service. By contrast, in the discipline of medicine, the fundamental commitment to caring is directly characterized in the diagnosis and treatment of human structural and functional problems manifested primarily in physical terms. The nature of the APRN (Advanced Practice Registered Nurse) role permits the direct focus on care and caring that is nursing while incorporating in limited ways the focus of medicine. An APRN does not practice medicine but rather draws upon and transforms characteristic medical ways of practice for nursing purposes, just as the practice of holistic medicine draws upon and transforms characteristic nursing ways of practice for medical purposes.

On the human side we learn from normalization process theory that the impact on health providers and healthcare delivery organizations will be immense [5]. We have seen that new providers such as engineers, informaticians, statisticians, communication and media specialists are entering the healthcare sector. Roles of physicians, nurses and hospitals will change drastically. Nurses' roles will change from a direct care provider to patient knowledge broker. There will be a higher need for advanced nursing roles such as advanced practice nurses and nurse practitioners to guide patients to manage their (mainly chronic) diseases. Hospitals will lack the certainty that patients come to the neighboring hospital as it used to be when they lacked any information to make an informed choice.

The amount of detail required in an assessment has both broadened and increased as ideas about the nature of health have changed [6]. Health is now regarded as more than the absence of illness, as a dynamic state, in which the individual responds and adapts to challenges, rather than a continuum. The individuality of each person means that everyone will respond to challenges in a unique way aimed at maintaining and preserving wellbeing. Inability to respond and cope effectively may result in illness. Health is, therefore, an individual experience rather than a single uniform state and it is possible to have a chronic condition, such as asthma, or a disability, and have a healthy life punctuated by episodes of ill health. Ideas about health must be based not only on how the individual is nowbut also on what that person may become in the future. Thinking about health requires the conceptualisation of multiple possibilities based on knowledge of the individual as a whole entity. A holistic approach to health is based on the recognition of the complexity of human existence and the diverse demands placed on individuals. In this context, health emerges as one of several, possibly competing, priorities, and health work becomes a process of enabling others to achieve what they regard as important and meaningful by helping them to manage or overcome obstacles.

In performing advanced health assessments the advanced practitioner demonstrates a commitment to an expanded and holistic concept of health [7]. In this context neither society nor professionals define health. It is not an ideal, unattainable state but a changing state of being experienced by the individual in response to events both within and outside that person. Health is more than the 


\section{Nursing \& Healthcare International Journal}

absence of disease and it is possible for the two to coexist within the individual. Thus a person with diabetes may describe herself as 'well for me'. This expanded idea of health has created opportunities for advanced practitioners to engage with individuals and populations in a wide variety of settings to promote an understanding of factors that affect health and how these may be managed. Individuals cannot take responsibility for every aspect of their health but there is, nevertheless, much that they can do to reduce the risk of serious illness or to minimise the potential complications of particular diseases or conditions.

Evidence for health care is generated through research, experience and the formulation of opinion [8]. Research is essentially the systematic search for truth or knowledge. As such, it is of fundamental importance to the beginning practitioner who must cultivate the habit of ensuring that their practice is supported by the best available evidence generated by research. For the advanced practitioner it is a critical mechanism for the improvement of practice. Often the advanced practitioner is dealing with intractable problems that necessitate further research to improve outcomes for their patients/clients. It is frequently the advanced practitioners who are in the best position to conduct that research.

At still another level, the managers of health service organisations will be concerned to identify those interventions and practices that produce optimal outcomes for patients/clients in the most efficient and cost-effective manner. The process of identifying those interventions and practices involves research, and again, the managers may well be best positioned, if not to actually conduct the research, to commission it.

\section{Assessment}

A key component of the advancing nursing role is that of holistic health assessment [9]. Holistic health assessment aims to capture data in a systematicand comprehensive format and includes all aspects of the patient's well being, including: physical and mental health, psychological status, social circumstances, beliefs and aspirations for their health and well being. It is important that repeated assessment is avoided, and for this reason the multidisciplinary team must develop a shared assessment document that can be used by all members of the team. Also, it must be agreed who will be responsible for what aspects of collecting data, to avoid either repeating or missing important information and to maximise the full potential of the team. The shared assessment document should form an integral part of the patient's pathway of care and treatment, and so there should be the ability to build upon information elicited during the acute phase of the patient's journey. Integrated care pathways are an ideal framework to foster both seamless integration of the acute and rehabilitative phases and interdisciplinary working.

Nurses are the only professional group within rehabilitation to provide a 24-hour service, 7 days per week, particularly within inpatient rehabilitation settings [10]. The 24-hour presence provides nurses with a unique opportunity to not only reinforce new skills learnt and incorporate them into everyday activities, but to evaluate patients' progress at different times of the day and night. For example, it is not uncommon for non-nurse members of the multidisciplinary team to declare a patient fit for discharge based on snapshot assessments during the day, necessitating nurse members of the team to report important issues such as: the patient suffers with confusion, nocturia, uncontrolled pain and a tendency to fall, etc. during the night.

\section{Ethics}

Nursing is a clinical practice that includes systematic problem solving (the nursing process) and nursing management of identified patient needs [11]. In planning patient care, the nurse makes countless decisions concerning nursing diagnoses, construction and implementation of nursing care plans, and evaluation of patients' progress toward health. Each decision requires that the nurse combine a wide range of facts (or data) with a set of values to determine what ought to be done to help the patient fulfill his or her health needs. The facts are drawn from many different types of information about the patient: his or her medical and psychosocial histories, physiological status, economic status, and aesthetic and religious orientations. However, collection and analysis of the facts alone can never lead to a conclusion that a particular nursing intervention is morally justified. To reach a conclusion about what is morally justified in nursing practice, the nurse must combine relevant facts with a set of values. Thus, the first task in nursing ethics is to identify the many evaluations that take place in nursing practice and to separate the moral from the nonmoral components in these evaluations.

The term nursing ethics is controversial. Some insist that nursing ethics is a unique field posing issues that cannot be understood fully by adapting the professional ethics of physicians. They insist on the term nursing ethics 


\section{Nursing \& Healthcare International Journal}

because it connotes the uniqueness of the moral problems that nurses face in the healthcare setting. On the other hand, others argue against the term. They suggest that there is really very little that is morally unique to nursing. The same ethical principles and the same moral issues emerge in the healthcare setting, whether one is a physician, nurse, or patient.

Biomedical ethics as a field presents a fundamental problem. As a branch of applied ethics, biomedical ethics becomes interesting and relevant only when it abandons the ephemeral realm of theory and abstract speculation and concerns itself with practical questions raised by real, everyday problems of health and illness. Much of biomedical ethics, especially as practiced within the health professions, is indeed oriented around the practical questions of what should be done in particular cases. Nursing, like other health professions, is case oriented. Yet, if those who must resolve the ever-increasing ethical dilemmas in health care-patients, family members, physicians, nurses, hospital administrators, and public policy makers - treat every case as entirely fresh, entirely novel, they will have lost perhaps the best way of reaching solutions: understanding the general principles of ethics and facing each new situation from a systematic ethical stance.

All nursing practice is necessarily informed, partly implicitly, by some nursing philosophy [12]. Such a philosophy embodies answers to a range of questions that are faced by any nurse. These include questions about the aims of care, professional-client relationships, working in teams and with colleagues, and wider questions about institutional, local or national policies. Although nursing involves activities other than patient or client care, such as health care research and management, it seems reasonable to view care as central, and to see the other activities as supporting this central one. But 'care' is too broad a notion to be of much help in clarifying the aims of nursing; care is the focus, but what are the aims of care? One example of the debate about nursing philosophy and the aims of nursing is represented in what has been called the shift 'from sick nursing to health nursing'. This shift which is dramatic in some areas of practice and incremental in others - is from doing things to patients towards working with them; from an approach that is 'disease-based' and expert-centred to one that is 'healthbased' and patient-centred. Such a shift follows from and reflects many developments, including changing patterns of ill health, emerging professional roles, an increase in consumerism, and emerging ideas about health promotion. But at its heart is what might be called an ethical shift, a shift in values which has two interrelated components. First, and rather crudely put, there is a move from treating people as passive towards treating them with respect as equals. This is not only because individuals have an important role to play in their own care, but also because individuals 'deserve' to be treated with respect, whether or not to do so is useful to professionals. Second, there is a move from equating the best interests of patients with being 'disease free' towards an acceptance that there is much more to well-being. Quality of life, peace of mind and self respect, for example, are legitimate concerns for a nurse, as well as disease management. These two components are closely related because one aspect of well-being, an aspect that many see as fundamental, is being able to make choices and have them treated with respect.

Many advanced practice nurses tend to be pragmatic in their view of nursing, focusing on whether or not something "works" in their practice and with their clients [13]. They look for actions and their consequences, believing that every effect has a discernible, hopefully treatable, cause. Clinical practitioners are often inclined to discard nursing theory as too abstract for practical purposes and too broad to have meaningful application to daily nursing practice. This view, which seems to eschew the value of philosophical thought, is actually a philosophical stance of its own. Whether we appreciate it or not, every nurse operates from a philosophical and theoretical base. The mature doctor of nursing practice (DNP) acknowledges this and seeks to understand the values, beliefs, and ideas that inform his or her daily practice. Practicing at the doctoral level is a highly complex, rich, multileveled experience that demands deeper insights if we are to effectively help to clients and represent profession.

\section{Conclusion}

Nurses are constantly following innovations and new technologies to use them in all forms for health promotion, disease prevention, and better quality nursing and treatment. The application of innovation is necessary in improving the quality of the healthcare process as well as nursing education. Problems in conducting health care, lack of staff and equipment insufficiency, as well as medical errors and omissions, motivate nurses and healthcare workers to research and find new solutions. In the process of providing health care, it is most important for a patient to feel safe. Regardless of his health conditions, nurse have obligation to provide the highest level of health care quality. 


\section{References}

1. Castledine G (2003) The Development of Advanced Nursing Practice in the UK. In: McGee P, et al. (eds), Advanced Nursing Practice, $2^{\text {nd }}(E d n)$, Blackwell Publishing Ltd, Oxford, UK, pp: 9.

2. Barton D, Davies A, Davies R (2017) Advandced practice in children and young people's nursing. In: Davies AM, et al. (eds), Children and Young People's Nursing - Principles for Practice, $2^{\text {nd }}(E d n)$, CRC Press, Taylor \& Francis Group, Boca Raton, USA, pp: 266.

3. Franjić S (2018) Woman as a gynecological patient. J Gynecol Res Obstet 4(1): 001-004.

4. Boykin A, Schoenhofer SO (2011) Caring and the Advanced Practice Nurse. In: Dunphy LM, et al. (eds), Primary Care-Art and Science of Advanced Practice Nursing, $3^{\text {rd }}(E d n)$ FA Davis Company, Philadelphia, USA, pp: 1344.

5. Sermeus W (2017) Global Society \& Big Data: Here's the Future We Can Get Ready For. In: Delaney CW, et al. Big Data-Enabled Nursing-Education, Research and Practice, Springer International Publishing AG, Cham, Switzerland, pp: 504.

6. McGee P (2003) Advanced Health Assessment. In: McGee $P$, et al. (eds), Advanced Nursing Practice, $2^{\text {nd }}$ (Edn.), Blackwell Publishing Ltd, Oxford, UK, pp: 8788.

7. Close A (2003) Advanced Practice and Health Promotion In: McGee P, et al. (Eds.), Advanced
Nursing Practice, $2^{\text {nd }}(E d n)$, Blackwell Publishing Ltd, Oxford, UK, pp: 112-113.

8. Pearson A, Field J, Jordan Z (2007) Evidence-Based Clinical Practice In Nursing And Health Care Assimilating Research, Experience and Expertise, Blackwell Publishing, Oxford, UK, 12: 156.

9. Booth S, Jester R (2007) The Rehabilitation Process In: Jester R (ed) Advancing Practice in Rehabilitation Nursing, Blackwell Publishing Ltd, Oxford, UK, pp: 23.

10. Jester R (2007) The Role of the Specialist Nurse Within Rehabilitation In: Jester R (ed) Advancing Practice in Rehabilitation Nursing (Chapter 2). Blackwell Publishing Ltd, Oxford, UK, pp: 15.

11. Fry ST, Veatch RM, Taylor C (2011) Case Studies in Nursing Ethics, $4^{\text {th }}(E d n)$, Jones \& Bartlett Learning, USA, pp: 506.

12. Cribb A (2014) The Ethical Dimension: Nursing Practice, Nursing Philosophy and Nursing Ethics. In: Tingle J, et al. (Eds.) Nursing Law and Ethics, $4^{\text {th }}$ (Edn), John Wiley \& Sons, Ltd, UK, pp: 23.

13. Eldridge CR (2011) Nursing Science and Theory: Scientific Underpinnings for Practice. In: Zaccagnini ME, et al. (eds), The Doctor of Nursing Practice Essentials-A New Model for Advanced Practice Nursing, Jones and Bartlett Publishers, USA, pp: 3. 